\title{
Accounting
}

\section{On the price volatility of steel futures and its influencing factors in China}

\author{
Tzuchia Chen ${ }^{a^{*}}$, Wenjing $\mathbf{L i}^{\mathbf{b}^{*}}$ and Shuyan $\mathbf{Y u}^{\mathrm{a}}$
}

${ }^{a}$ Department of Business Administration, International College, Krirk University, Bangkok, 10220, Thailand

${ }^{b}$ Department of Financial Management, China-Asian International College, Dhurakij Pundit University. Bangkok, Thailand

\section{H R O N I C L E}

\section{Article history:}

Received: November 28, 2020

Received in revised format:

December 282020

Accepted: February 7, 2021

Available online:

February 7, 2021

Keywords:

Deformed steel bars futures

Hot rolled coils futures

GARCH model

\section{A B S T R A C T}

Steel futures have the function of price discovery and hedging. Steel related enterprises can judge the hedging strategy through the direction of steel futures price volatility, and reasonably avoid the risk brought by price volatility. Therefore, it is particularly important to study steel futures price volatility and its influencing factors. Because steel futures in China have characteristics of peak and rear tail aggregation, the paper constructs Model of GARCH $(1,1)$ to make positive analysis of futures price volatility and its influencing factors of deformed steel bars and hot rolled coils, and the following conclusions have been drawn: (1) The volume and open interest of deformed steel bars have very significant explanatory ability to futures price volatility of deformed steel bars; (2) The volume and open interest of hot rolled coils also have very significant explanatory ability to futures price volatility of hot rolled coils; (3) The sustainable capacity of the price volatility of deformed steel bars and hot rolled coils is relatively small; (4) Iron ore price have no obvious explanatory ability to futures price volatility. Finally, some managerial implications and suggestions are derived from the analysis of the proposed model.

\section{Introduction}

The futures market is an important indicator that affects the development of the financial system for any country, and hedging is one of the most important functions of the futures market. Because various causes affecting the futures price continue to play a role and form a final futures price, the futures price volatility can accurately reflect the supply and demand situation and the changing trend of the market, improve the allocation of resources, and help maintain the stability of the social real economy. China is the country that produces the most quantity of steel in the world; steel has become one of the pillars of China's economy, and it can also represent the level of China's economic development. Steel is widely used in real estate construction, railway construction, ship building, automobile manufacturing and so on. Since most of the raw materials of steel, iron ores, have to be imported from abroad, if another financial crisis breaks out or there exist factors like the current Sino-US trade war that affect the financial aspect, the spot price of Chinese steel will fluctuate strongly. Liu (2011) concluded from his research that the steel spot price volatility would affect the same direction fluctuation of the steel futures price in the current period, so steel futures have the function of price discovery and hedging in China. Therefore, it is particularly important to study the price volatility of steel futures; steel enterprises can judge the hedging strategy through the direction of steel futures price volatility and reasonably avoid the risk brought by price volatility.

\footnotetext{
* Corresponding author.

E-mail address: 167176713@qq.com (T.Chen)
} 
Since 2014, due to the slowdown of economic development, steel futures prices in China have been in the stage of downward fluctuations, and then China has implemented a loose credit strategy, resulting in a surge in demand for real estate in China at that time, further increasing the demand for steel, leading to upward fluctuations in steel futures prices. The steel futures market has experienced a series of rapid ups and downs, so the volatility of the trading market has increased, and the risk of traders participating in the investment has become greater and greater, so it is necessary to have a clear model to determine the development trend of steel futures volatility. There are 149 futures companies and 4 futures exchanges in China. This paper mainly studies steel futures of Shanghai Futures Exchange. Steel futures include deformed steel bars, hot rolled coils and wire rods futures. Since the trading volume of wire rods futures in recent years has been almost zero, the study in this paper has excluded wire rods futures.

By studying the price volatility characteristics and influencing factors of steel futures in Shanghai Futures Exchange, this paper provides important theoretical support for studying the price volatility and influencing factors of the steel futures market in China. The rest of this paper is organized as follows. By reviewing literature, the proposed model is presented to describe the volatility of steel futures as proposed in Section 3. Empirical study is performed in Section 4. Finally, some managerial implications and suggestions are derived from the analysis of the proposed model in Section 5.

\section{Literature review}

In the futures market, futures price volatility refers to the degree of change in futures prices. The academic research on the characteristics of financial assets price volatility has experienced a long process, and the related literature on futures volatility can be divided into three categories: the researches of commodity futures price volatility, measurement model of commodity futures price volatility - ARMA and GARCH related model and research on the influencing factors of commodity futures price, which are described as follows:

The futures market is an important indicator that affects the development of the financial system for any country, and hedging is one of the most important functions of the futures market. Because various causes affecting the futures price continue to play a role and form a final futures price, the futures price volatility can accurately reflect the supply and demand situation and the changing trend of the market, improve the allocation of resources, and help maintain the stability of the social real economy. China is the country that produces the most quantity of steel in the world; steel has become one of the pillars of China's economy, and it can also represent the level of China's economic development. Steel is widely used in real estate construction, railway construction, ship building, automobile manufacturing and so on. Since most of the raw materials of steel, iron ores, have to be imported from abroad, if another financial crisis breaks out or there exist factors like the current Sino-US trade war that affect the financial aspect, the spot price of Chinese steel will fluctuate strongly. Liu (2011) concluded from his research that the steel spot price volatility would affect the same direction fluctuation of the steel futures price in the current period, so steel futures have the function of price discovery and hedging in China. Therefore, it is particularly important to study the price volatility of steel futures; steel enterprises can judge the hedging strategy through the direction of steel futures price volatility and reasonably avoid the risk brought by price volatility. Since 2014, due to the slowdown of economic development, steel futures prices in China have been in the stage of downward fluctuations, and then China has implemented a loose credit strategy, resulting in a surge in demand for real estate in China at that time, further increasing the demand for steel, leading to upward fluctuations in steel futures prices. The steel futures market has experienced a series of rapid ups and downs, so the volatility of the trading market has increased, and the risk of traders participating in the investment has become greater and greater, so it is necessary to have a clear model to determine the development trend of steel futures volatility. There are 149 futures companies and 4 futures exchanges in China. This paper mainly studies steel futures of Shanghai Futures Exchange. Steel futures include deformed steel bars, hot rolled coils and wire rods futures. Since the trading volume of wire rods futures in recent years has been almost zero, the study in this paper has excluded wire rods futures.

By studying the price volatility characteristics and influencing factors of steel futures in Shanghai Futures Exchange, this paper provides important theoretical support for studying the price volatility and influencing factors of the steel futures market in China. The rest of this paper is organized as follows. By reviewing literature, the proposed model is presented to describe the volatility of steel futures as proposed in Section 3. Empirical study is performed in Section 4. Finally, some managerial implications and suggestions are derived from the analysis of the proposed model in Section 5.

\section{Literature review}

In the futures market, futures price volatility refers to the degree of change in futures prices. The academic research on the characteristics of financial assets price volatility has experienced a long process, and the related literature on futures volatility can be divided into three categories: the researches of commodity futures price volatility, measurement model of commodity futures price volatility - ARMA and GARCH related model and research on the influencing factors of commodity futures price, which are described as follows:

Mandelbrot (1963) first found that the distribution of some economic time series had the characteristics of a thick tail, and in the whole process of variance changing with time, variance changes with relatively small range of variation occur in some time 
periods. That is, the change of price volatility has agglomeration. Fama (1965) found in his study on the price volatility of financial assets that even the price volatility of actively-traded financial speculative assets would remain relatively stable in any period. The research results show that the distribution of the price yield time series of futures and other financial assets markets presents a leptokurtic distribution. Compared with the normal distribution, the frequency distribution is more near the mean value, and the tail of the distribution is relatively thick, and there is skewness generally. Therefore, the matching of the least square method with the price yield fluctuation of financial assets under the hypothetical condition of normal distribution will show skewness. Hagerman (1978) studied the volatility of security price yield and found two characteristics of volatility: the first was that its distribution was not subject to normal distribution and had skewness; the second was that the distribution curve showed the characteristics of sharp peak and thick tail, and the peak value was larger than 3. By taking the stock market crash in the United States in the 1980s as the dividing point, Schwert (1990) made an empirical analysis on the volatility of securities prices by adopting the ARCH model, the results showed that the volatility range of securities prices after the crash was 2.5 times higher than that before the crash, which proved the existence of asymmetric effect. Cheung and Lai (1993) studied the long memory characteristics of futures price volatility, the results indicated that various futures showed different long memory characteristics.

The measurement models of commodity futures price volatility mainly include ARMA and GARCH models. After Engle (1982) put forward the ARCH model to analyze the heteroscedasticity of time series, Bollerslev (1986) put forward the GARCH model. GARCH model is a regression model specially designed for financial data. Besides the similarities to the ordinary regression model, GARCH makes further modelling of the variance of the error. The GARCH model is especially suitable for volatility analysis and prediction. Compared with the ARMA model, the advantage of the GARCH model is that it can represent a highorder model in a relatively simple form, which makes it easier to identify and estimate the model, and which is more suitable for estimation in the case of a small amount of calculation. Brooks, Faff, McKenzie and Mitchell (2000) used the ARMA model, GARCH model and AP-GARCH model to simulate the price volatility of LME commodity futures contracts, and compared with actual results, it was found that the GARCH model had the best simulation effect. Therefore, this paper uses the GARCH model to study the price volatility of steel futures. Bae and Karolyi (1994) selected GARCH model to make an empirical study on the price volatility of SP500 and Nikkei225. The results showed that the price volatility of SP500 and Nikkei225 had asymmetric effects. Watkins and McAleer (2005) showed that macroeconomic fundamentals such as consumption, production and stock levels have very good explanatory ability of the volatility of mental futures by AR(1) and GARCH(1,1) models on the London Metal Exchange (LME). Kang, Kang and Yoon (2009) investigate the price volatility for Brent, Dubai, and West Texas Intermediate (WTI) crude oil markets to conclude that the CGARCH and FIGARCH models are feasible than GARCH and IGARCH models for these three crude oil prices.

In the case of the study on the influencing factors of commodity futures prices, Cornell (1981) first studied the relationship between the volume and the price of futures products, it was found that the trading volume would also affect the price, and the two were positively correlated. After that, Bigman, Goldfarb and Schechtman (1983) studied wheat, corn and soybean futures, he used the least square method to prove that the futures prices of the three futures products were unbiased estimates of the corresponding spot market prices on the last delivery date, while forward futures prices were biased estimates. Garcia, Leuthold and Zapatd (1986) studied the relationship between the volume and the price of futures, and found that there existed a lag guiding relationship between the trading volume and price volatility of five kinds of commodity futures, and the fluctuation of futures price would be reflected in the trading volume. Rosenberg and Birdzell (1986) studied copper, zinc and aluminum futures at LIFFE, analyzed influencing factors of futures prices by using a variety of statistical methods, and proved that copper, aluminum and zinc futures were strong and effective futures markets, which fully reflected market information, public and non-public information in the market was all reflected in futures prices. Adrangi, Chatrath, and Christie (2000) studied and analyzed influencing factors of gold futures from the perspective of macro factors, proving that macro factors did affect price changes of gold futures, among which GDP, PPI and CPI had significant impacts. Kumar (2019) examined the linear and nonlinear relations between returns volatility and trading volume for the Indian currency futures market and they concluded that trading volume helps predict the futures prices. Caporin, Chang and McAleer (2019) analyzed the relationships among the S\&P 500 Index and futures prices, returns and volatility of crude oil, natural gas and ethanol to show that futures prices and returns will vary depending on the trading range based on a day, a week, or a month.

From the above analysis, it can be seen that the research on futures price volatility in our country mainly focuses on agricultural products futures. Domestic scholars have carried out many researches on influencing factors of futures prices, most of which are active commodity futures in China, such as soybean and gold. Because the development of the overseas market is earlier than that of China, Chinese scholars study the domestic futures market on the basis of learning from foreign literature. Existing researches mainly focus on analyses of the price volatility of stock and agricultural products, and effectiveness of stock and agricultural product futures markets. There are many reasons that affect the variability of the price volatility of steel futures time series. Generally speaking, the influencing factors of steel price volatility can be divided into two points. 1. Volume: Volume refers to the total number of futures contracts concluded in a certain period of time, usually calculated on each trading day, which reflects the fact that funds enter or withdraw from the market. So, the volume is an important basis for judging the trend of futures contracts. Generally speaking, a futures contract with a rising price must have very large volume and active price, 
whereas a futures contract with a falling price must have relatively small volume. Karpoff (1987) verified for the first time that there existed a generally positive relationship between futures price volatility and futures volume. 2. Open interest: Open interest refers to the total amount of futures contracts that have been concluded but not yet delivered or hedged. It is usually the direction of the development of the futures market in depth and will affect the ability to buy and sell at a certain price or range. Once the trader feels the risk is too great, beyond the limit that oneself can bear, the trader will close or hold a position, wait and see. The increase in open interest is the beginning of a transaction, and the reduction in open interest means the end of a transaction. Bessembinder, Coughenour, Seguin and Smoller (1995) took open interest as a variable of market depth for study for the first time, and concluded that open interest had a positive impact on futures price. Ragunathan and Peker (1997) studied the price volatility of centralized futures at Sydney Futures Exchange in the same way, and obtained a similar conclusion. So, we think that volume and open interest, as significant indicators of the steel futures trading market, are the most direct indicators to reflect the strategy of the trading buyer and seller. When rising behaviors occur in the futures trading market, the futures volume also increases accordingly, which indicates that the rising momentum is abundant; and the futures open interest can help to confirm other technical indicators. Both parties to the market transaction can judge how much money has been injected into the market, or how much money has been withdrawn from the market based on the change in futures open interest, which will help to understand the forecasting trend of futures volatility. Therefore, this study chooses the volume and open interest as explanatory variables that can directly reflect the price volatility of steel futures. Based on this, the following research assumptions are put forward:

$\mathrm{H}_{\mathrm{a} 1}$ : The volume and open interest of deformed steel bars have the explanatory ability of the price volatility of deformed steel bars futures.

$\mathrm{H}_{\mathrm{a} 2}$ : The volume and open interest of hot rolled coils have the explanatory ability of the price volatility of hot rolled coils futures.

$\mathrm{H}_{\mathrm{a} 3}$ : Iron ore price has the explanatory ability of the price volatility of futures.

The research framework diagram of this study is as follows:

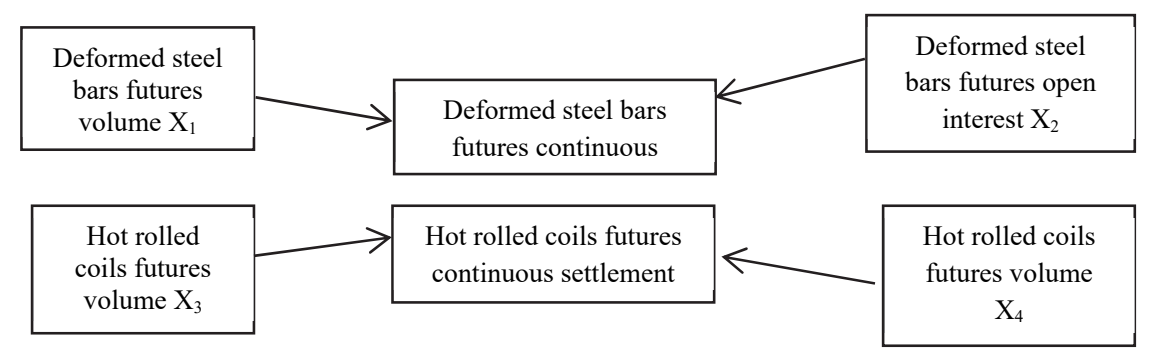

\section{Research method}

Fig. 1. Research framework diagram

In the futures trading market, once a long cycle of weekly or monthly or quarterly data is selected as research data, the results obtained will not conform to real events. Because there are too many interval days between them, drastic changes may not be detected, they will not be sufficient for short-term analysis either, so in this study price data of daily transactions are taken as the research object of this study. It should be noted that all futures contracts have different expiration time, and expiration dates of all futures contracts have a limit. So, when a futures contract expires, it will become invalidated. Steel futures in this study will have many contracts with different expiry months that are simultaneously traded on the same date, so this is also a feature of steel futures, that is, the so-called discontinuity. In this study, data of steel futures contracts are processed continuously. The continuous processing method is to select the data of steel futures contracts of a month with more open interest and volume and frequent trading in the current month as the representative data of continuous data. After the arrival of delivery time of the recent steel futures contract, the next steel future contract with the same time interval is chosen. In this way, the continuous time series of each steel futures can be generated. In this paper, the daily closing price, open interest and volume data of "deformed steel bars continuity" and "hot rolled coils continuity" directly provided by China's WIND database are selected as the data objects studied in this paper. The time of deformed steel bars data provided is from January 6, 2017 to December 31, 2018, with 484 sets of data, after the first difference, there are 483 sets of data. In this study, data are increased to 100 times of the original data. The relative fluctuation of deformed steel bars futures is defined as:

$$
R T=\left(\operatorname{Ln}\left(C R_{t}\right)-\operatorname{Ln}\left(C R_{t-1}\right)\right) \times 100
$$

where $C R_{t}$ is consecutive closing price of deformed steel bars on this trading date of $\mathrm{t}$. Volume and open interest of deformed steel bars futures are $\mathrm{X}_{1}$ and $\mathrm{X}_{2}$ respectively, as shown below:

$$
X_{1}=\left(\operatorname{Ln}\left(X_{1 t}\right)-\operatorname{Ln}\left(X_{1 t-1}\right)\right) \times 100
$$


where $X_{1 t}$ is the volume of deformed steel bars on this trading date of $t$.

$$
X_{2}=\left(\operatorname{Ln}\left(X_{2 t}\right)-\operatorname{Ln}\left(X_{2 t-1}\right)\right) \times 100
$$

where $X_{2 t}$ is the open interest of deformed steel bars on this trading date of $t$. The time of hot rolled coils data provided is also from January 6, 2017 to December 31, 2018, with 484 sets of data, after the first difference, there are 483 sets of data. The relative fluctuation of hot rolled coils futures is defined as:

$$
P T=\left(\operatorname{Ln}\left(C P_{t}\right)-\operatorname{Ln}\left(C P_{t-1}\right)\right) \times 100
$$

where $C P_{\mathrm{t}}$ is the consecutive closing price of hot rolled coils on the trading date of $t$. Similarly, the volume and open interest of hot rolled coils futures are $\mathrm{X}_{3}$ and $\mathrm{X}_{4}$, respectively,

$$
X_{3}=\left(\operatorname{Ln}\left(X_{3 t}\right)-\operatorname{Ln}\left(X_{3 t-1}\right)\right) \times 100
$$

where $X_{3 \mathrm{t}}$ is the volume of hot rolled coils on the trading date of $\mathrm{t}$,

$$
X_{4}=\left(\operatorname{Ln}\left(X_{4 t}\right)-\operatorname{Ln}\left(X_{4 t-1}\right)\right) \times 100
$$

where $X_{4 \mathrm{t}}$ is the open interest of hot rolled coils on the trading date of $\mathrm{t}$. Whether the financial data time series meets the normal distribution, generally skewness $(S)$, kurtosis $(K)$ and normal test are used in the study to make statistics of the characteristics. The formula is expressed as follows:

$$
\begin{aligned}
& S=\frac{E(X-E(X))^{2}}{(D(X))^{3 / 2}}, \\
& K=\frac{E(X-E(X))^{4}}{(D(X))^{2}} .
\end{aligned}
$$

If the time series of the random variable is normally distributed, then skewness is 0 and kurtosis is 3 . If skewness is $>0$, it indicates that skewness is tilted to the right. If skewness $<0$, it indicates that skewness is tilted to the left. If kurtosis $>3$, it indicates that it has the characteristics of a peak. If $0<$ kurtosis $<3$, it indicates that the time series belongs to a flat peak. At present, the commonly used way to test normal distribution is JB test. The JB test expression is:

$$
J B=\frac{n}{6}\left[S^{2}+\frac{(K-3)^{2}}{4}\right] .
$$

The JB test results of $X_{1}, X_{2}, X_{3}$ and $X_{4}$ significantly reject the assumption of normal distribution. In addition, econometrics requires that the stationarity of the sequence must be tested before studying different variables. Only the results obtained with the characteristics of stationarity are true and valid. In this study, an ADF test is used to verify stationarity. Then, GARCH is used to establish the volatility model of steel futures and Granger Causal Relation Test is used to study the correlation of variables. In the GARCH model, there are two model regression processes involved:

$$
y_{t}=\chi_{t}{ }^{\prime} \beta+\varepsilon_{t} \text {, }
$$

and

$$
h_{t}=\alpha_{0}+\sum_{i+1}^{q} \alpha_{i} \varepsilon_{t-1}^{2}
$$

where $y_{t}$ is explained variable, $x_{t}$ is explanatory variable, $h_{t}$ is conditional variance of $\varepsilon_{\mathrm{t}}$ at the moment of t, $\alpha_{0}$ is constant term, $\sum_{i=1}^{q} \alpha_{i} \varepsilon_{t-i}^{2}$ is ARCH, $\sum_{j=1}^{p} \theta_{j} h_{t-j}$ is GARCH.

\section{Empirical analysis}

\subsection{Descriptive statistics, stationarity test and normality test of deformed steel bars futures price}

The results of descriptive statistics on the data of relative volatility time sequence (RT) of deformed steel bars futures price are as follows: 


\section{Table 1}

Table of basic statistical characteristics of relative volatility time sequence (RT) of deformed steel bars futures price

\begin{tabular}{cccc}
\hline & Sample Size & & 483 \\
\hline Mean value & 0.032321 & Skewness & -0.753400 \\
Median & 0.098474 & Kurtosis & 6.260335 \\
Max value & 5.768085 & JB normal test statistics & 269.6172 \\
Min value & -9.472162 & JB normal test P value & $0.000000^{* * *}$ \\
Standard deviation & 1.962334 & ADF test P value & $0.0000^{* * *}$ \\
\hline *Indicating 10\% significance; **Indicating 5\% significance; ***Indicating 1\% significance.
\end{tabular}

From the basic statistics of descriptive characteristics of relative volatility time sequence (RT) of deformed steel bars futures price, it can be known that skewness $(\mathrm{S})$ is negative $(-0.753400<0)$, indicating that compared with the standard normal distribution, this sequence presents a left-skewed form; kurtosis $(\mathrm{K})$ is positive and greater than $3(6.260335>3)$ with the characteristic of obvious sharp peak and thick tail. The $\mathrm{p}$ value of JB normal test is infinitely close to 0 , which shows that the assumption of 0 is obviously rejected under the $1 \%$ confidence level, and the time sequence does not comply with normal distribution. It can be seen from the ADF unit root test that the sequence (RT) is a stationary sequence at a significant level of $1 \%$.

\subsection{Granger causal relation test of price volatility, volume and open interest of deformed steel bars futures}

It can be seen from Table 1 that the relative volatility time sequence (RT) of deformed steel bars price conforms to the stationarity of ADF unit root test, so Granger causal relation test can be used to clearly know the correlation of the variables, as shown in Table 2, it can be found from the $\mathrm{p}$ value result of Granger causal relation test: there exists a causal relationship between the relative volatility $(\mathrm{RT})$, open interest $\left(\mathrm{X}_{1}\right)$ and volume $\left(\mathrm{X}_{2}\right)$ of deformed steel bars futures price. $\left(\mathrm{X}_{1}\right)$ and $\left(\mathrm{X}_{2}\right)$ also have a twoway causal relationship.

\subsection{Correlation analysis of price volatility and variance of deformed steel bars futures: GARCH $(1,1)$ model}

\section{Table 2}

Granger causal relation test of explanatory variables and explained variables of deformed steel bars

\begin{tabular}{ccc}
\hline Relation & F Value & $P$ Value \\
\hline $\mathrm{X}_{1} \rightarrow \mathrm{RT}$ & 6.26005 & $0.0021^{* * *}$ \\
$\mathrm{X}_{2} \rightarrow \mathrm{RT}$ & 5.78522 & $0.0033^{* * *}$ \\
$\mathrm{X}_{1} \rightarrow \mathrm{X}_{2}$ & 3.63627 & $0.0271^{* *}$ \\
$\mathrm{X}_{2} \rightarrow \mathrm{X}_{1}$ & 5.68950 & $0.0036^{* * *}$ \\
\hline
\end{tabular}

*Indicating $10 \%$ significance; $* *$ Indicating $5 \%$ significance; $* * *$ Indicating $1 \%$ significance.

To study the influencing factors of the price volatility of deformed steel bars futures, and the relationship between deformed steel bars futures price, volume $\left(\mathrm{X}_{1}\right)$ and open interest $\left(\mathrm{X}_{2}\right)$, GARCH $(1,1)$ model is selected according to AIC, SC and HQ criteria. The GARCH model constructed is as follows,

$$
\begin{aligned}
& R T_{t}=\mu+\phi_{1} x_{1 t}+\phi_{2} x_{2 t}+\varepsilon_{t}, \varepsilon_{t} \sim N\left(0, h_{t}\right), \\
& h_{t}=\alpha_{0}+\alpha_{1} \varepsilon_{t-1}{ }^{2}+\beta_{1} h_{t-1}{ }^{2}+\phi_{1} x_{1 t}+\phi_{2} x_{2 t} .
\end{aligned}
$$

GARCH $(1,1)$ model parameter analysis: results of the price volatility (RT), volume (X1) and open interest (X2) of deformed steel bars futures, and the test results are shown in Table 3:

\section{Table 3}

GARCH $(1,1)$ model parameters of the price volatility $(\mathrm{RT})$ and explanatory variables of deformed steel bars futures

\begin{tabular}{cc}
\hline Coefficient & GARCH $(1,1)$ \\
\hline$\alpha_{0}$ & $0.0000^{* * *}$ \\
$\alpha_{1}$ & $0.0000^{* * *}$ \\
$\beta_{1}$ & $0.0000^{* * *}$ \\
$\phi_{1}$ & $0.0000^{* * *}$ \\
$\phi_{2}$ & $0.0000^{* * *}$ \\
$\alpha_{1}+\beta_{1}$ & 0.0000 \\
\hline
\end{tabular}

*Indicating $10 \%$ significance; $* *$ Indicating $5 \%$ significance; $* * *$ Indicating $1 \%$ significance

It can be seen from the parameter estimation in Table 3 that when both the volume $\left(\mathrm{X}_{1}\right)$ and open interest $\left(\mathrm{X}_{2}\right)$ are put into the GARCH $(1,1)$ model for interpretation, $\mathrm{p}$ values of $\left(\mathrm{X}_{1}\right)$ and $\left(\mathrm{X}_{2}\right)$ are very significant. This shows that the volume and open 
interest have very good explanatory ability of deformed steel bars futures price at the same time. Therefore, in actual trading, when the volume and open interest increase, the price volatility of deformed steel bars futures may also increase accordingly; in the same way, when the volume and open interest become smaller, the price volatility variance of deformed steel bars futures may also decrease accordingly. It indicates that when $\mathrm{X}_{1}$ and $\mathrm{X}_{2}$ are added at the same time, GARCH $(1,1)$ is stable. The residual sequence Q (36) (Ljung-Box Test) of the GARCH $(1,1)$ model is $>0.05$, so it is judged that the model has a higher degree of fitting.

\subsection{Descriptive statistics, stationarity test and normality test of hot rolled coils futures price}

The results of descriptive statistics on the data of relative volatility time sequence (RT) of hot rolled coils futures price are in Table 4. From the basic statistics of descriptive characteristics of relative volatility time sequence (PT) of hot rolled coils futures price, it can be known that skewness $(\mathrm{S})$ is negative $(-0.557713<0)$, indicating that compared with the standard normal distribution, this sequence presents a left-skewed form; kurtosis $(\mathrm{K})$ is positive and greater than 3 (5.193246>3) with the characteristic of obvious sharp peak and thick tail. The $\mathrm{p}$ value of JB normal test is infinitely close to 0 , which shows that the assumption of 0 is obviously rejected under the $1 \%$ confidence level, and the time sequence does not comply with normal distribution. It can be seen from the ADF unit root test that the sequence (PT) is a stationary sequence at a significant level of $1 \%$.

Table 4

Table of basic statistical characteristics of relative volatility time sequence (PT) of hot rolled coils futures price

\begin{tabular}{|c|c|c|c|}
\hline \multicolumn{2}{|c|}{ Sample Size } & \multicolumn{2}{|c|}{483} \\
\hline Mean value & 0.004496 & Skewness & -0.557713 \\
\hline Median & 0.054805 & Kurtosis & 5.193246 \\
\hline Max value & 5.237734 & JB normal test statistics & 122.0991 \\
\hline Min value & -7.899590 & JB normal test $\mathrm{P}$ value & $0.000000 * * *$ \\
\hline Standard deviation & 1.798550 & ADF test $\mathrm{P}$ value & $0.000 * * *$ \\
\hline
\end{tabular}

*Indicating 10\% significance; **Indicating 5\% significance; ***Indicating 1\% significance

\subsection{Granger causal relation test of price volatility, volume and open interest of hot rolled coils futures}

It can be seen from Granger causal relation test that volume (X3) and open interest (X4) have a two-way causal relationship in Table 5, whereas hot rolled coils futures price (PT) and volume (X3) have a causal relationship.

Table 5

Table of Granger causal relation test of explanatory variables and explained variables of hot rolled coils

\begin{tabular}{ccc}
\hline Relation & F Value & PValue \\
\hline $\mathrm{X}_{3} \rightarrow \mathrm{X}_{4}$ & 3.67361 & $0.0261^{* *}$ \\
$\mathrm{X}_{4} \rightarrow \mathrm{X}_{3}$ & 3.03734 & $0.0489^{*}$ \\
$\mathrm{PT} \rightarrow \mathrm{X} 3$ & 2.77133 & $0.0636^{*}$ \\
\hline${ }^{*} \mathrm{H}$ & & \\
\hline
\end{tabular}

*Indicating $10 \%$ significance; $* *$ Indicating $5 \%$ significance; $* * *$ Indicating $1 \%$ significance

\subsection{Correlation analysis of price volatility and variance of hot rolled coils futures: GARCH $(1,1)$ model}

To study the influencing factors of the price volatility of hot rolled coils futures, and the relationship between hot rolled coils futures price $(\mathrm{PT})$, volume $\left(\mathrm{X}_{3}\right)$ and open interest $\left(\mathrm{X}_{4}\right)$, GARCH $(1,1)$ model is selected according to AIC, SC and HQ criteria. The GARCH model constructed is as follows:

$$
\begin{aligned}
& P T_{t}=\operatorname{ARMA}(1,1)+\varphi_{3} x_{3 t}+\varphi_{4} x_{4 t}+\varepsilon_{t}, \varepsilon_{t} \sim N\left(0, h_{t}\right), \\
& h_{t}=\alpha_{2}+\alpha_{3} \varepsilon_{t-1}{ }^{2}+\beta_{2} h_{t-1}^{2} .
\end{aligned}
$$

GARCH $(1,1)$ model parameter analysis: results of the price volatility $(\mathrm{PT})$, volume $\left(\mathrm{X}_{3}\right)$ and open interest $\left(\mathrm{X}_{4}\right)$ of hot rolled coils futures are in Table 6. It can be seen from the parameter estimation in the Table 6 that when both the volume $\left(\mathrm{X}_{3}\right)$ and open interest $\left(\mathrm{X}_{4}\right)$ of hot rolled coils are put into the GARCH $(1,1)$ model for interpretation, the statistical $\mathrm{p}$ values of $\left(\mathrm{X}_{3}\right)$ and $\left(\mathrm{X}_{4}\right)$ are strongly significant at the confidence level of $1 \%$. This shows that the volume and open interest have strong explanatory ability of hot rolled coils futures price at the same time. Therefore, similar with deformed steel bars, in the actual trading, when the volume and open interest increase, the price volatility variance of hot rolled coils futures may also increase accordingly; in the same way, when the volume and open interest become smaller, the price volatility variance of hot rolled coils futures may also decrease accordingly. Because, when (X3) and (X4) are added at the same time, GARCH (1,1) is stable. The residual sequence of GARCH $(1,1)$ model $Q>0.05$, so it is judged that the model has a higher degree of fitting. 


\section{Table 6}

Table of GARCH $(1,1)$ model parameters of the price volatility (PT) and explanatory variables of hot rolled coils futures

\begin{tabular}{ccc}
\hline Coefficient & GARCH $(1,1)$ & $0.0143^{* *}$ \\
\hline$\alpha_{2}$ & $0.0033^{* *}$ \\
$\alpha_{3}$ & $0.0000^{* * *}$ \\
$\beta_{2}$ & $0.0031^{* * *}$ \\
$\varphi_{3}$ & $0.0001 * *$ \\
$\varphi_{4}$ & 0.0143 \\
$\alpha_{2}+\beta_{2}$ & 38.632 \\
$\mathrm{Q}(36)$ & & \\
\hline
\end{tabular}

*Indicating 10\% significance; **Indicating 5\% significance; ***Indicating $1 \%$ significance.

\subsection{Summary}

In this study, empirical analyses of prices and influencing factors of deformed steel bars and hot rolled coils futures have been made. Firstly, data have been obtained according to the research content, and then descriptive statistics of deformed steel bars and hot rolled coils income data and models to be used are constructed, finally, the following results are obtained: (1) The volume and open interest of deformed steel bars have very significant explanatory ability of the price volatility of deformed steel bars futures; (2) The volume and open interest of hot rolled coils also have very significant explanatory ability of the price volatility of hot rolled coils futures; (3) The sustainability of the price volatility of deformed steel bars and hot rolled coils is relatively small; (4) In this paper, models of iron ore price are tried to be constructed, however, these influencing factors have no obvious explanatory ability of futures price volatility. Next, analysis of causes for the empirical results is made in this paper to prove that the assumption of $\mathrm{H} 1$ and $\mathrm{H} 2$ are tenable, while the assumption of $\mathrm{H} 3$ are untenable.

\section{Conclusion}

\subsection{Discussion}

When GARCH $(1,1)$ models of deformed steel bars and hot rolled coils are added with respective volume and open interest, it is found that the explanatory variables can have obvious explanatory ability of explained variables, which indicates that the increasing trading volume that is taking place can affect the price volatility of steel futures, possible reasons are as follows:

(1) The policy of cutting overcapacity and banning "steel bars with scrap steel as raw material" in 2018 has been a great success. The macro-control of this policy requires to shut down heavily polluting and energy-intensive enterprises and unregistered workshops or to suspend business for rectification, even large enterprises like Ansteel and Liuzhou Iron and Steel Group also have to upgrade their production equipment. The success of this policy has partly reduced the growth rate of steel production. In the first half of 2017, China's steel output reached 419,860,000 tons, up 4.5\% year on year, cumulative output of steel reached more than 500,000,000 tons. Steel production is greater than crude steel production, so steel price rises, investors and acute speculators smell the opportunity to buy deformed steel bars futures or hot rolled coils futures, because both the volume and open interest have increased, the price will also fluctuate upward.

(2) A few years ago, depressed market prices of steel made steel futures trading unable to recover after a setback either, the inventory in the entire steel industry chain was very small. Since 2017 and 2018, China's comprehensive development of a welloff society formulated in the "13th Five-year Plan" and the "Belt and Road Initiative" have triggered the rise of international steel demand, so there is a new round of infrastructure construction and transformation, in addition, high speed rail construction expand to overseas, the construction of a new round of commercial residential building starts, all these have resulted in a large demand for steel. In the GARCH $(1,1)$ models of deformed steel bars and hot rolled coils and show that the continuity of the overall fluctuation is relatively weak, for example, once a certain impact affects the steel futures market, the impact will not last very long and will be absorbed by the market quickly, the reason may be as follows:

(1) The pricing power of iron ores, raw materials of steel products, is not in China, iron ore prices are not fixed by the government, and the steel futures market itself is characterized by competition and monopoly, which makes the degree of marketization not strong, so the persistence of price volatility in the steel futures trading market is not high either.

(2) Investors in China's steel futures market are relatively special, those that take a long position are mainly large institutions actually, while those who take a short position are small retail investors. The main purpose of these large institutions is to reduce risk or avoid risk hedging, so the transaction amount is large and not active; the main purpose of retail investors is to pursue profit and arbitrage, so they are mostly speculators. Large institutions judge to buy or sell mainly according to international steel futures prices and market information, they are mainly engaged in long-term trading to avoid the impact of price volatility on 
the entire steel industry, so their degree of activity is not high. In contrast, retail investors with higher degree of activity but less money have insufficient influence on the persistence of price volatility and sharp price fluctuations.

(3) In terms of steel futures trading system factors, to curb excessive speculation, China stipulates that the minimum margin in steel futures trading is $9 \%$, which is $4 \%$ higher than that of other contracts. This policy raises the threshold of getting started, and further restrains the activity degree of the price volatility of the steel futures market, so sometimes steel futures price rises to a certain extent, but it is difficult to fall. However, to stimulate the market liquidity in steel futures, the smallest transaction quantity is stipulated to be 10 tons instead of 100 tons for other products, according to reason, the market liquidity should be increased, but from the empirical study in this paper, the persistence of such option is not very strong, indicating that this system of reducing the smallest transaction quantity leaves a lot to be desired.

\subsection{Research suggestion}

Suggestion for large investment organizations:

(1) Because most of the steel futures investors are large steel organizations, these enterprises can set up an investment hedging department to predict the volatility of steel futures in the way of empirical model, so as to achieve the purpose of avoiding losses and hedging. Steel organizations can also reach long-term cooperation with futures companies, with the latter's help, steel organizations can formulate investment portfolio to suit themselves.

(2) Investment organizations can establish multi-level hedging strategies. Currently, the strategy of investment organizations is mainly to buy the same products with different expiration time, such operation is relatively simple, but the effect is general. Investment organizations can buy deformed steel bars futures and hot rolled coils futures at the same time, and formulate hedging strategies among different steel futures. Such multi-level hedging can effectively increase profits and further avoid risks. Suggestion for futures retail speculators:

(1) China's futures have developed for more than 30 years, and the trading links are relatively standardized. Therefore, investors who participate in futures trading are all experienced people, investors should strengthen their professional knowledge and ability, and improve their sensitivity to the market. According to the research results of this paper, the trend of increase and decrease of the current volume and open interest can be analyzed as the basis of whether to invest or not at the time of investment. These two factors have great influence on the price volatility of steel futures.

(2) Investors can pay more attention to state policies, such as the "13th Five-year Plan" and the "Belt and Road Initiative". The content of the "13th Five-year Plan" is mainly the comprehensive well-off society, various infrastructure construction needs to be increased. At this time, the demand for steel will increase and the price will rise. This is the best time to invest.

Suggestion for the futures management department:

(1) More transactions in line with international contracts need to be reached. Steel trading is one of the commodities with the largest trading volume in futures trading, and the number of investors participating is also very large. With the establishment of China (Guangxi)-ASEAN Free Trade Area and Shanghai Free-Trade Zone, the global economic integration and national internationalization are proceeding slowly. China's futures trading should cherish the opportunity, face the challenge, and promote the goal of futures trading internationalization. The Futures management department can formulate international contracts different from those within the country, laying the foundation for futures internationalization. The benefits of internationalization can also be publicized to enterprises, helping steel companies to be actively in line with international standards; finally, many favorable policies can be formulated to attract foreign investment and open the door to internationalization.

(2) Strengthen own ability and assist enterprises in establishing relevant hedging departments. Send special professionals to key enterprises for one-to-one guidance, and help enterprises to establish hedging departments under the premise of sufficient conditions. With the continuous improvement of the futures market, the varieties are constantly enriched, and the futures market is more specialized, which requires the management organization to improve its own management ability so as to manage the futures market well and assist steel companies in making good hedging strategies.

\subsection{Limitation of the study and future work}

(1) The research period of this paper was from January 6, 2017 to December 28, 2018. And the source of the research data is historical summary and not prediction, so the empirical results show the characteristics of history. During this period, there were many policy announcements on steel futures, so the future research direction can be added with the discussion of the influencing factors of events. 
(2) In this paper, the volatility and influence factors of steel futures are studied, but only the influence factors are directed at. In the future, the investment portfolio risk or the leverage of steel futures can be studied.

\section{Funding}

The author received financial support from Ming Zhong International Education (Thailand) Co., Ltd. for the research, authorship, and/or publication of this article.

\section{References}

Bae, K. H., \& Karolyi, G. A. (1994). Good news, bad news and international spillovers of stock return volatility between Japan and the US. Pacific-Basin Finance Journal, 2(4), 405-438.

Bessembinder, H., Coughenour, J. F., Seguin, P. J., \& Smoller, M. M. (1995). Mean reversion in equilibrium asset prices: Evidence from the futures term structure. The Journal of Finance, 50(1), 361-375.

Bigman, D., Goldfarb, D., \& Schechtman, E. (1983). Futures market efficiency and the time content of the information sets. Journal of Futures Markets, 3(3), 321-334.

Bollerslev, T. (1986). Generalized autoregressive conditional heteroskedasticity. Journal of econometrics, 31 (3), $307-327$.

Brooks, R. D., Faff, R. W., McKenzie, M. D., \& Mitchell, H. (2000). A multi-country study of power ARCH models and national stock market returns. Journal of International money and Finance, 19(3), 377-397.

Caporin, M., Chang, C. L., \& McAleer, M. (2019). Are the S\&P 500 index and crude oil, natural gas and ethanol futures related for intra-day data?. International Review of Economics \& Finance, 59, 50-70.

Cheung, Y. W., \& Lai, K. S. (1993). Do gold market returns have long memory?. Financial Review, 28(2), $181-202$.

Cornell, B. (1981). The relationship between volume and price variability in futures markets. The Journal of Futures Markets (pre-1986), 1(3), 303.

Engle, R. F. (1982). Autoregressive conditional heteroscedasticity with estimates of the variance of United Kingdom inflation. Econometrica: Journal of the Econometric Society, 50(4), 987-1007.

Garcia, P., Leuthold, R. M., \& Zapata, H. (1986). Lead-lag relationships between trading volume and price variability: New evidence. The Journal of Futures Markets (1986-1998), 6(1), 1.

Hagerman, R. L. (1978). More evidence on the distribution of security returns. The Journal of Finance, 33(4), $1213-1221$.

Kang, S. H., Kang, S. M., \& Yoon, S. M. (2009). Forecasting volatility of crude oil markets. Energy Economics, 31(1), 119125.

Karpoff, J. M. (1987). The relation between price changes and trading volume: A survey. Journal of Financial and quantitative Analysis, 22(1), 109-126.

Kumar, S. (2019). The relationship between trading volume and exchange rate volatility: linear or nonlinear?. International Journal of Managerial Finance, 15(1), 19-38.

Liu, H. (2011). The influence of steel futures on spot price volatility in China. China Business and Market, 11(12), 53-56.

Mandelbrot, B. (1963). The variation of certain speculative prices. Journal of Business, 36(4), 394-419.

Ragunathan, V., \& Peker, A. (1997). Price variability, trading volume and market depth: evidence from the Australian futures market. Applied Financial Economics, 7(5), 447-454.

Rosenberg, N., \& Birdzell, L. (1986). How the West Grew Rich: The Economic Transformation of the Western World. New York, Basic Books.

Watkins, C., \& McAleer M. (2005). Related commodity markets and conditional correlations. Mathematics and Computers in Simulation, 68(5-6), 567-579.

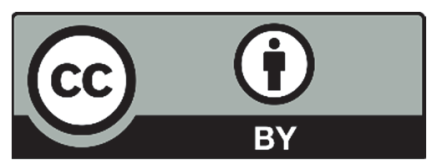

(C) 2021 by the authors; licensee Growing Science, Canada. This is an open access article distributed under the terms and conditions of the Creative Commons Attribution (CC-BY) license (http://creativecommons.org/licenses/by/4.0/). 